\title{
ADAPTIVENESS OF CATTLE EGRET'S (BubulCus IbIS) FORAGING
}

\author{
Aeshita Mukherjee \\ Ornithologist, National Tree Growers Cooperative Federation Limited, Opposite IRMA, National Dairy Development Board Campus, \\ Anand, Gujarat 388001, India. \\ E-mail: aeshita@ntgcf.irm.ernet.in
}

\begin{abstract}
Cattle Egrets (Bubulcus ibis) feeding in close association with cattle catch insect prey at a significantly higher rate and expend less energy than do those foraging alone. Cattle Egrets once had a strong association with grazing cattle, but have now shifted themselves behind tractors specially in inundated agricultural fields. Captures per minute were 2.06 for the egrets feeding near the head, 0.85 while sharing with a cow and lowest when the egrets were feeding alone. The egrets with exclusive access to a cow always foraged better and caught significantly more number of prey than the others. A comparison between cattle and tractor in terms of capture per minute reveals the tractor to be more efficient in exposing the prey. Probably it wont be unfair to rename a Cattle Egret a Tractor Egret looking at its adaptiveness in foraging efficiently with tractors!
\end{abstract}

\section{Keywords \\ Cattle Egret, foraging, agricultural fields, tractor}

\section{Introduction}

Heatwole (1965) and Grubb (1976) have shown that Cattle Egrets (Bubulcus ibis) feeding in close association with cattle catch insect prey at a significantly higher rate and expend less energy than those foraging alone. According to the recent trend and fast transformation in the agricultural practices and change in the cropping pattern, birds dependent on agriculture have also shown a coinciding foraging adaptiveness. Cattle Egrets which once had a strong association with grazing cattle, have now shifted themselves behind tractors specially in inundated agricultural fields. The purpose of this study is to confirm the earlier results and to evaluate the adaptiveness of the Cattle Egrets' site tenacity with cow and compare the results with rewards while moving along the tractor and among human beings working in the field.

Received 19 February 2000 Accepted 1 September 2000

\section{Materials and Methods}

Observations were made of

(a) egrets foraging with cattle (group A),

(b) egrets around tractor (group B) and

(c) egrets accompanying human workers (group C)

in the agricultural area of Gujarat Agricultural University from 0700 to 1900 hours during August 1999. The Cattle Egrets were divided into three categories in each group, viz.

(i) those foraging near the head of the cattle (within $2 \mathrm{~m}$.),

(ii) sharing with the cattle ( $2 \mathrm{~m}$. or more) and

(iii) away from the cattle (more than $10 \mathrm{~m}$.).

Similar categorization was followed for making observation with group B and group C. Each category was observed for five minutes per hour. Alternate day of the week was assigned for taking observations on a particular group. Therefore in a month, four observation of each group comprising of 240 minutes on each category was taken.

Cattle Egrets always jerk back the head characteristically when swallowing prey (Hancock \& Kushlan, 1984). The number of head-jerk swallows and number of steps per minute were counted as the measure of energy intake and expenditure, respectively. Grasshoppers, the dominant component in the diet of Cattle Egrets in the study site by Jenni (1973), were abundant in the pasture.

Cattle Egrets fed away from the cattle, fed solitarily within $2 \mathrm{~m}$. of cow or had shared a cow. The feeding sites within $2 \mathrm{~m}$. of a cow were numbered according to whether egrets eyes were in front of cows, between the shoulder and the hips or absolutely behind the cow. Analysis were performed with the distribution KruskalWallis test with Duncans multiple range test (Steel \& Torrie, 1980).

\section{Results}

In the initial hours (0700 to 0845), egrets within $2 \mathrm{~m}$. of the cow never foraged for five minutes consecutively in just one zone. The egrets often made short quick dashes into another zone after an emergant of disturbed insects and again returned to the previous zone near the cattle. The fluctuation in the time interval 
Table 1. Foraging efficiencies of Cattle Egret

\begin{tabular}{l|lll|lll|llc}
\hline \multirow{2}{*}{ Observation } & \multicolumn{3}{|c|}{ Cattle } & \multicolumn{3}{c}{ Tractor } & \multicolumn{3}{c}{ Human being } \\
\cline { 2 - 11 } & With & Sharing & Alone & With & Sharing & Alone & With & Sharing & Alone \\
\hline Min. watched & 240 & 240 & 240 & 240 & 240 & 240 & 240 & 240 & 240 \\
Captures & 496 & 206 & 141 & 644 & 309 & 154 & 474 & 197 & 162 \\
Steps & 6592 & 8241 & 9845 & 4135 & 4372 & 9982 & 5985 & 6345 & 6854 \\
Steps/min. & 27.46 & 34.34 & 41.02 & 17.23 & 18.22 & 41.59 & 24.93 & 26.44 & 28.55 \\
Steps/capture & 13.30 & 40.00 & 69.82 & 6.42 & 14.14 & 64.82 & 12.60 & 32.20 & 42.30 \\
Capture/min. & 2.06 & 0.85 & 0.58 & 2.68 & 1.28 & 0.64 & 1.97 & 0.82 & 0.67 \\
Efficiency ratio & 6.50 & 47.06 & 120.37 & 2.39 & 11.04 & 101.28 & 6.39 & 39.26 & 63.13 \\
\hline
\end{tabular}

was short and variable. Of the 107 Cattle Egrets foraging with a cow, 83.18 per cent were near the head, 13.08 per cent by the side and 3.74 per cent about the rear. Capture per minute were 2.06 for egrets feeding near the head, 0.85 while sharing with a cow and lowest when the egrets were feeding alone. To forage alone the egrets had to take maximum steps per minute (41.02) compared to while with or sharing a cow (Table 1).

It was often evident that the new flock of egrets (58\%) that try to join the existing one near a cow were driven off rather quickly $($ Mean $=7.8+/-5.7 \mathrm{sec})$. About 32 per cent left the cow within five minutes. Only five times we observed both resident egret and the new arrival forage for more than five minutes within $2 \mathrm{~m}$. of the same cow.

The egrets with exclusive access to a cow always foraged better and caught significantly more number of prey than the others. Table 1 shows egrets with exclusive right to a cow had significantly higher foraging efficiency (steps per capture divided by capture per minute; Grubb, 1976) and caught slightly more prey per minute than did those foraging away from the cattle, or than those sharing the cow. Heatwole (1965) mentions egrets defending cattle but the cattle per egret ratio in his study area was five egrets per cow whereas Grubb (1976) indicated $2.4+/-$ 1.2 cows per egret $(n=12)$. The present study shows 1.5 cows per egret $(n=16)$ which is quite different.

Similar trend was obtained when the egrets foraged along with the tractor or with field workers. The capture per minute was highest with tractor (2.68) followed by the cattle (2.06) and comparatively lower while feeding along with the field workers (1.97). Capture per minute was significantly higher in case of egrets sharing with a tractor (1.28) while the value was on par with cattle and human being (Table 1). Grasshopper was the dominant component in the diet of Cattle Egrets in the same study site (Borad et al., 1999).

\section{Discussion}

It is apparent from the study that it is adaptive for an egret to defend its exclusive use of cow. The study also confirms that it pays an egret to share a cow than foraging away from the cattle completely. Therefore the tendency to defend a cow is weak and easily swamped by large influx of egrets. The function of aggressive behaviour shown by some egrets is uncommon. Similar situation can be compared with antbirds feeding around army ant colonies (Willis, 1968; Hilty, 1974).

Table 2. Kruskal-Wallis Test with Dunn's Multiple Comparisons for Cattle Egrets foraging

\begin{tabular}{lll}
\hline & Comparisons & P value \\
\hline Steps/minutes & With cow : sharing cow & 0.69 \\
& With cow : alone & $<0.001$ \\
& Sharing cow : alone & $<0.001$ \\
Captures/minute & With cow : sharing cow & $<0.001$ \\
& With cow : alone & $<0.001$ \\
& Sharing cow : alone & 0.68 \\
Steps/minutes & With tractor : sharing tractor & 0.63 \\
& With tractor : alone & $<0.001$ \\
& Sharing tractor & $<0.001$ \\
Captures/minute & With tractor : sharing tractor & $<0.001$ \\
& With tractor: alone & $<0.001$ \\
& Sharing tractor : alone & 0.64 \\
& With human: sharing human & 0.67 \\
Steps/minute & With human: alone & $<0.001$ \\
& Sharing human: alone & $<0.001$ \\
Captures/minute & With human: sharing human & $<0.001$ \\
& With human: alone & $<0.001$ \\
& Sharing human: alone & 0.66 \\
\hline
\end{tabular}


We presume that the egrets were defending the vicinity of the cattle's, but at the same time they might be defending a critical individual distance. Many a times the egrets were foraging peacefully less than a metere apart from the cattle. Birds species dependant on food clumped on small discontinuous patch tend to be solitary, while those dependant on food available evenly distributed tend towards a group dwelling Grubb (1976). If the differential prey vulnerability is analogous to prey differential abundance, the behavioral modifications of Cattle Egret was noticed. When prey is highly vulnerable locally (around cattle) a solitary (anti-social) system emerges from the group feeding socially in the absence of cattle on homogeneously vulnerable prey (Grubb, 1976).

A comparison between cattle and tractor in terms of capture per minute reveals tractor to be more efficient in exposing the prey expenditure in terms of steps per capture also confirms the same. Probably it wouldn't be unfair to rename a Cattle Egret a Tractor Egret looking to its adaptiveness in foraging efficiently with tractors.

\section{Acknowledgement}

I am thankful to Dr. B.M. Parasharya of Gujarat Agricultural University for his valuable suggestions during the study period and for improving the text. I am also thankful to Dr. S.N. Biswas, IRMA, for his guidance in performing the statistical tests. Facilities rendered by National tree Growers Cooperative Federation are highly acknowledged.

\section{References}

Borad, C.K., A. Mukherjee and M.V. Asnani (Communicated). Role of Cattle Egret in controlling insect pest in Kheda District, Gujarat. Grubb, R.C. ( 1976). Adaptiveness of foraging in the Cattle Egret. Wilson Bull. 88(1): 145-148.

Hancock, J. and J. Kushlan (1984). The Herons Handbook. Croom Helm, London.

Heatwole, H. (1965). Some aspects of association of Cattle Egrets with cattle. Anim. Behav. 13: 79-83.

Hilty, L.S. (1974). Notes on birds at swarms of army ants in highlands of Colombia. Wilson Bull. 86(4): 479-481.

Jenni, D.A. (1973). Regional variation in the food of nesting Cattle Egrets. Auk 94: 689-700.

Steel, R.G.D. and J.H. Torrie (1980). Principles and Procedures of Statistics: A biometrical Approach, $2^{\text {nd }}$ edition. McGraw Hill, Kogakush Ltd., London.

Willis, E.O. (1968). Taxonomy and behaviour of Pale-faced Antbird. Auk 85: 253-264. 